\title{
Radiometric consistency assessment of hyperspectral infrared sounders
}

\author{
L. Wang ${ }^{1}$, Y. Han ${ }^{2}$, X. Jin ${ }^{3}$, Y. Chen ${ }^{1}$, and D. A. Tremblay ${ }^{4}$ \\ ${ }^{1}$ Earth System Science Interdisciplinary Center/Univ. of Maryland, College Park, MD, USA \\ ${ }^{2}$ NOAA/NESDIS/Center for Satellite Applications and Research, College Park, MD, USA \\ ${ }^{3}$ Earth Resources Technology Inc. at NOAA/NESDIS/STAR, Laurel, MD, USA \\ ${ }^{4}$ Science Data Processing Inc. at NOAA/NESDIS/STAR, College Park, MD, USA \\ Correspondence to: L. Wang (wlikun@umd.edu)
}

Received: 15 May 2015 - Published in Atmos. Meas. Tech. Discuss.: 14 July 2015

Revised: 19 October 2015 - Accepted: 26 October 2015 - Published: 19 November 2015

\begin{abstract}
The radiometric and spectral consistency among the Atmospheric Infrared Sounder (AIRS), the Infrared Atmospheric Sounding Interferometer (IASI), and the Crosstrack Infrared Sounder (CrIS) is fundamental for the creation of long-term infrared (IR) hyperspectral radiance benchmark data sets for both intercalibration and climate-related studies. In this study, the CrIS radiance measurements on Suomi National Polar-orbiting Partnership (SNPP) satellite are directly compared with IASI on MetOp-A and MetOp-B at the finest spectral scale and with AIRS on Aqua in 25 selected spectral regions through simultaneous nadir overpass (SNO) observations in 2013, to evaluate radiometric consistency of these four hyperspectral IR sounders. The spectra from different sounders are paired together through strict spatial and temporal collocation. The uniform scenes are selected by examining the collocated Visible Infrared Imaging Radiometer Suite (VIIRS) pixels. Their brightness temperature (BT) differences are then calculated by converting the spectra onto common spectral grids. The results indicate that CrIS agrees well with IASI on MetOp-A and IASI on MetOp-B at the long-wave IR (LWIR) and middle-wave IR (MWIR) bands with $0.1-0.2 \mathrm{~K}$ differences. There are no apparent scenedependent patterns for BT differences between CrIS and IASI for individual spectral channels. CrIS and AIRS are compared at the 25 spectral regions for both polar and tropical SNOs. The combined global SNO data sets indicate that the CrIS-AIRS BT differences are less than or around $0.1 \mathrm{~K}$ among 21 of 25 spectral regions and they range from 0.15 to $0.21 \mathrm{~K}$ in the remaining four spectral regions. CrIS-AIRS BT
\end{abstract}

differences in some comparison spectral regions show weak scene-dependent features.

\section{Introduction}

Hyperspectral infrared (IR) radiance measurements from satellite sensors contain valuable information on atmospheric temperature and humidity profiles, greenhouse gases, clouds, and surface characteristics. These measurements are used not only to retrieve atmospheric temperature and humidity profiles, but more importantly, to be directly assimilated into numerical weather prediction (NWP) models as inputs (Chahine et al., 2006). Moreover, owing to their hyperspectral nature and accurate radiometric and spectral calibration, hyperspectral IR radiances have been used as a reference to independently assess spectral and radiometric calibration accuracy of broad- or narrow-band IR instruments (Goldberg et al., 2011; Wang et al., 2009a, 2011), as well as for longterm climate change monitoring (Wielicki et al., 2013), strict testing of climate model outputs (Huang et al., 2008), and validation of numerical weather model analyses and reanalyses (Wang et al., 2010).

Carried on NASA's Earth Observing System Aqua spacecraft and launched in May 2002, the Atmospheric Infrared Sounder (AIRS) is a grating infrared sounder that measures the thermal infrared spectrum with 2378 spectral channels with a nominal spectral resolution of $v / \Delta v=1200$ (Chahine et al., 2006). The Infrared Atmospheric Sounding Interferometer (IASI) is the first operational interferometer in space 


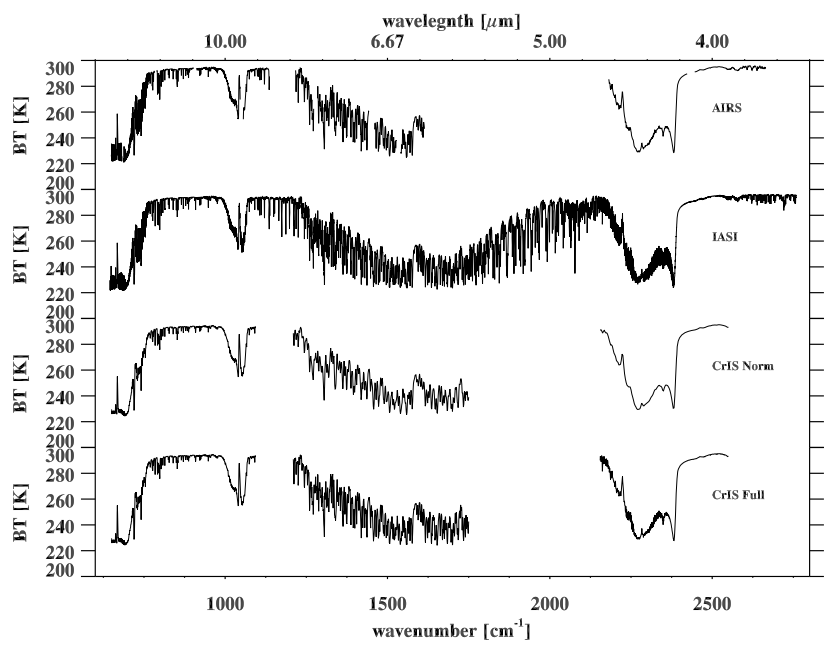

Figure 1. AIRS, CrIS, and IASI spectra simulated by LBLRTM using an identical tropical atmospheric profile over the ocean. The description of CrIS normal and full spectral resolution mode can be found in the text.

measuring the $3.5-16.4 \mu \mathrm{m}\left(610-2825 \mathrm{~cm}^{-1}\right)$ spectrum in 8461 spectral channels with a spectral sampling interval of $0.25 \mathrm{~cm}^{-1}$, successfully launched on MetOp-A in October 2006 and MetOp-B in September 2012 (Hilton et al., 2012). The Cross-track Infrared Sounder (CrIS) on the Suomi National Polar-orbiting Partnership (SNPP) and future Joint Polar Satellite System (JPSS) is a Fourier transform spectrometer that provides soundings of the atmosphere with 1305 spectral channels (Han et al., 2013). The current SNPP and future JPSS CrIS, combined with the existing AIRS on Aqua and IASI on MetOp-A and MetOp-B, will accumulate decades of hyperspectral infrared measurements. Therefore, the radiometric and spectral consistency among AIRS, IASI, and CrIS is fundamental for the creation of long-term IR hyperspectral radiance benchmark data sets for both intercalibration and climate-related studies.

In this study, we directly compare the SNPP CrIS radiance measurements with the AIRS on Aqua and IASI on MetOp-A and MetOp-B at orbital crossing points of satellites through 1 year of the data, the so-called simultaneous nadir overpasses (SNO) (Cao et al., 2004). The purpose is to evaluate radiometric consistency and differences of these four hyperspectral IR sounders. This is the first ever opportunity for intercalibration because four hyperspectral IR sounders observe the Earth and atmosphere at the same spectral regions from different satellites. Several similar studies have been presented recently. For example, D. Jouglet from Centre national d'études spatiales (CNES) (Jouglet et al., 2014) compared IASI (on MetOp-A and MetOp-B) with AIRS and CrIS at 33 broad pseudo-bands through regional averaging of the soundings pixels over a $300 \mathrm{~km} \times 300 \mathrm{~km}$ area around the orbit crossing point with $\sim 20$ min differences. At each pseudo-channel, the inter-compared spectra are averaged to get the similarity of the spectral functions. Tobin et al. (2013a, b) compared CrIS and IASI/MetOp-A along CrIS spectral grids and CrIS with AIRS at six spectral ranges with 10 wavenumber intervals, using the so-called "big circle SNOs", where each sounder's observations were collected within a $100 \mathrm{~km}$ circle of the SNO location with 20 min time differences. Through collecting a large ensemble of collocated samples, it is believed that the spatial collocation errors are random and Gaussian distributed. A weighted mean difference between the two sensors was computed independently for each spectral channel by using the spatial variability of each SNO as the weights. Strow et al. (2013a) also compared CrIS with IASI using high-latitude SNO observations and CrIS with AIRS level-1c data that are converted from AIRS level-1b data by removing popping channels and adding the missing channels. However, to the best of our knowledge, all of these studies have not been published in peer-reviewed literature. The uniqueness of this independent study is focused on comparison of four current operational hyperspectral sounders (CrIS with AIRS; CrIS with IASI on MetOp-A and MetOp-B) with strict spatial and temporal collocation criteria. With enough collocated measurements that are able to cover instruments' dynamic range, we believe that the strict collocation can reduce collocation uncertainties according to our previous studies and thus can effectively identify the measurement differences at an instrument calibration level if the size of comparison samples is statistically large enough (Wang et al., 2009a, b).

The paper is organized as follows: Sect. 2 summarizes CrIS, AIRS, and IASI instruments and the data sets used in this study, Sect. 3 describes the methodology, Sect. 4 presents the results, and Sect. 5 concludes the paper.

\section{Instruments and data sets}

The instrument characteristics of AIRS, CrIS, and IASI are summarized in Table 1, including satellite platform, launch date, local equator crossing time, spatial and spectral resolution, number of channels, and spectral coverage. Figure 1 shows typical spectra of AIRS, CrIS, and IASI simulated by the line-by-line radiative transfer model (LBLRTM) using a typical tropical atmospheric profile over the ocean (Clough et al., 1992, 2005).

AIRS on Aqua is a grating IR spectrometer and disperses the radiation from the Earth scene onto 17 linear arrays of $\mathrm{HgCdTe}$ detectors on a focal plane with 2378 IR channels (Chahine et al., 2006). Covering the spectral bands of 3.74$4.61,6.20-8.22$, and $8.8-15.4 \mu \mathrm{m}$ with a nominal spectral resolution of $v / \Delta v=1200$, AIRS views the ground through a cross-track rotary scan mirror and provides $\pm 49.5^{\circ}$ ground coverage in every $2.67 \mathrm{~s} \mathrm{scan}$ cycle. A total of 90 ground footprints are observed for each scan. The AIRS IR spatial resolution is $13.5 \mathrm{~km}$ from the nominal altitude of $705.3 \mathrm{~km}$ on a Sun-synchronous satellite with an ascending node at 13:30 local solar time (LST). The AIRS level 1B Version 5 data are 
Table 1. Instrument characteristics of CrIS, AIRS, and IASI.

\begin{tabular}{|c|c|c|c|}
\hline & CrIS & AIRS & IASI \\
\hline Satellite platform & Suomi NPP & Aqua & $\begin{array}{l}\text { MetOp-A } \\
\text { MetOp-B }\end{array}$ \\
\hline Launch date & 28 Oct 2011 & 4 May 2002 & $\begin{array}{l}19 \text { Oct } 2006 \\
17 \text { Sep } 2012\end{array}$ \\
\hline $\begin{array}{l}\text { Local equatorial } \\
\text { crossing times }\end{array}$ & $13: 30$ & $13: 30$ & $09: 30$ \\
\hline $\begin{array}{l}\text { Spatial resolution } \\
\text { (nadir) }\end{array}$ & $14.0 \mathrm{~km}$ & $13.5 \mathrm{~km}$ & $12.0 \mathrm{~km}$ \\
\hline Technique & FTS $^{\mathrm{a}}$ & Grating & FTS \\
\hline Number of channels & $\begin{array}{l}1305 \text { (normal spectral } \\
\text { resolution) } \\
2211 \text { (full spectral } \\
\text { resolution) }\end{array}$ & 2378 & 8461 \\
\hline Spectral coverage & $\begin{array}{l}\text { LWIR, MWIR, and } \\
\text { SWIR with gaps }\end{array}$ & 17 spectral bands with gaps & $\begin{array}{l}\text { LWIR, MWIR, and SWIR bands } \\
\text { without gaps }\end{array}$ \\
\hline $\begin{array}{l}\text { Spectral sampling } \\
\text { resolution }\left(\mathrm{cm}^{-1}\right)\end{array}$ & $\begin{array}{l}\text { LWIR: } 0.625(0.625)^{b} \\
\text { MWIR: } 1.25(0.625) \\
\text { SWIR: } 2.5(0.625)\end{array}$ & $0.4-2.1$ (varying with bands) & 0.25 \\
\hline Reference & Han et al. (2013) & Chahine et al. (2006) & Hilton et al. (2012) \\
\hline
\end{tabular}

a FTS represents Fourier transform sounder.

$\mathrm{b}$ The numbers in the brackets indicate the spectral resolution at full spectral resolution mode.

used in this study, which were distributed by NASA Goddard Earth Sciences (GES) Data and Information Services Center (DISC).

IASI on MetOp-A and MetOp-B is a Michelson interferometer that measures IR radiation in the three IR spectral bands between wavelengths of 3.6 and $15.5 \mu \mathrm{m}$ with a spectral resolution of $0.5 \mathrm{~cm}^{-1}$ (after spectral apodization) and a spectral sampling interval of $0.25 \mathrm{~cm}^{-1}$ (Hilton et al., 2012). IASI is in a Sun-synchronous polar orbit at $819 \mathrm{~km}$ and crosses the Equator at 09:30 LST in a descending node. The IASI observations are obtained by a step-scanning mirror covering $\pm 47.85^{\circ}$ range in 30 steps in every 8.0 s scan cycle, with $3.3^{\circ}$ for each step (normal mode). At each step, the field of regard (FOR) includes $2 \times 21.25^{\circ}$ FOVs (field of view) with a pixel resolution of $12 \mathrm{~km}$ at nadir, each positioned in the cross-track and along-track direction located at $\pm 0.825^{\circ}$. We use resampled, apodized, and calibrated spectra with 8461 spectral samples (i.e., the IASI level 1C radiance products), which were directly downloaded from European Organisation for the Exploitation of Meteorological Satellites (EUMETSAT) data center. Hereafter, IASI/A and IASI/B are used to refer to IASI on MetOp-A and MetOp-B, respectively.

CrIS is a step-scan Fourier transform spectrometer onboard the Suomi NPP spacecraft at a nominal altitude of $824 \mathrm{~km}$ in a Sun-synchronous orbit with local equatorial crossing times of $\sim$ 13:30 (ascending) and $\sim$ 01:30 (descending). CrIS takes $8 \mathrm{~s}$ for each scan sweep, each collecting 34 fields of regard (FORs). Among them, 30 are of the Earth and 4 are the embedded space and blackbody calibration views. The scan mirror stepwise "stares" at the Earth step by step in the cross-track direction from $-48.3^{\circ}$ to +48.3 with a $3.3^{\circ}$ step angle, equaling a $2200 \mathrm{~km}$ swath width on the Earth. Nine field stops define the $3 \times 3$ detector array for each IR wavelength band, which are arrayed as $3 \times 30.963^{\circ}$ circles and separated by $1.1^{\circ}$. The estimated on-orbit absolute spectral calibration uncertainty is less than $3 \mathrm{ppm}$ in the long-wave and mid-wave bands (Strow et al., 2013b), and the estimated $3 \sigma$ radiometric uncertainty for all Earth scenes is less than $0.3 \mathrm{~K}$ in the long-wave band and less than $0.2 \mathrm{~K}$ in the mid-wave and short-wave bands (Tobin et al., 2013b). The geolocation uncertainty for near nadir pixels is less than $0.4 \mathrm{~km}$ in the cross-track and in-track directions (Wang et al., 2013). CrIS can be operated in two modes: normal and full spectral resolution mode. CrIS radiance spectrum (without apodization) covers three IR bands from 650 to 1095,1210 to 1750 , and 2155 to $2550 \mathrm{~cm}^{-1}$ with spectral resolutions of $0.625,1.25$, and $2.5 \mathrm{~cm}^{-1}$ at the normal operational mode (a total of 1305 spectral channels) and with an identical spectral resolution of $0.625 \mathrm{~cm}^{-1}$ in all three bands at the full spectral resolution (FSR) mode (a total of 2211 channels). The CrIS instrument is currently operated at the normal node, but several tests have been performed at the full spectral resolution mode on 23 February 2012, 12 March 2013, and 27 August 2013. CrIS has been operating in the FSR mode since 4 December 2014. The ground processing software - Interface Data Processing Segment (IDPS) - was updated almost at the same time, which still processed the FSR raw data records (RDR) into the normal resolution sensor data records (SDR) in order to keep the consistency of operational 

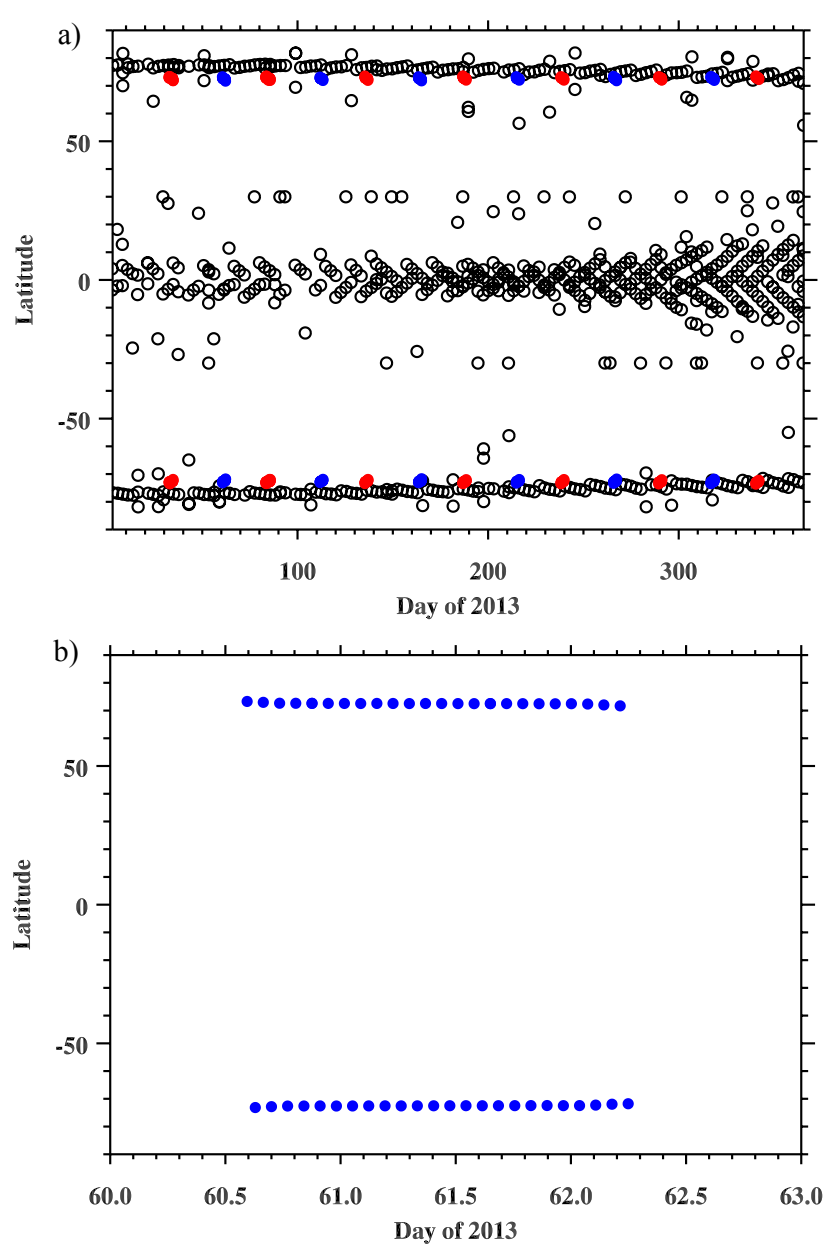

Figure 2. (a) Time series of latitude distribution of SNO events of CrIS-AIRS (black), CrIS-IASI/A(red), and CrIS-IASI/B (blue), and (b) enlarged plot for the SNO event of CrIS-IASI/B on 1-3 March 2013.

data sets. After launch, an intensive post-launch evaluation was performed by the CrIS SDR team, focusing on validating its spectral, radiometric, and geometric calibration. Accordingly, the calibration algorithms have been improved and calibration parameters have been refined during an intensive calibration and validation period (Han et al., 2013). The last significant updates took place on 17 February 2014, including (1) the release of IDPS version MX8.2 with correction of central FOV instrument line shape equation and (2) the upload of Engineering Packets V36 with updated nonlinearity coefficients. Therefore, the CrIS radiance data used in this study were processed using JPSS Algorithm Development Library (ADL) version 4.0 with Engineering Packets V36, which is comparable to IDPS version MX8.2. The radiance differences were examined for the data processed by ADL and IDPS and the results suggest that the differences are at the negligible level. As a final note, the CrIS SDR data used in this study have been apodized using a Hamming function
(Han et al., 2013). The effective spectral resolution increases by a factor of 1.82 for all three bands after apodization.

\section{Methods}

\subsection{Spatial collocation}

For pairs of Sun-synchronous polar-orbiting satellites with different altitudes, theoretically, their nadir points cross each other within a few seconds near the north and south polar regions (typically in the $70-80^{\circ} \mathrm{N}$ and $70-80^{\circ} \mathrm{S}$ latitude zones) for a certain time period (dependent on orbit altitude difference), which are referred to as SNO observations (Cao et al., 2004). When a SNO occurs, the radiometers from both satellites view the Earth at the same place and same time from different altitudes, which greatly reduces the comparison uncertainties related to the difference of satellite observational time and viewing geometries. One of the limitations of highlatitude SNO-based comparison is that the instruments cannot be compared over a full brightness temperature (BT) dynamic range. However, Aqua and SNPP satellites basically have the same equatorial crossing time $(\sim 13: 30 \mathrm{LST})$ but different altitudes (SNPP's altitude is $824 \mathrm{~km}$ and Aqua's is $705 \mathrm{~km}$ ). Consequently, every few days, these two satellites are stacked nearly on top of each other with a wealth of coincident data through the full Aqua swath, yielding temporal and spatial coincidences varying with latitude, though with a larger time difference than high-latitude SNOs (Uprety et al., 2013). This provides ample opportunities to compare SNPP CrIS measurements with Aqua AIRS at different latitudes with a large dynamic range.

Figure 2a shows time series of SNO latitudes for CrISAIRS, CrIS-IASI/A, and CrIS-IASI/B. Since SNPP and Aqua satellites are both in afternoon orbits, the SNO events between SNPP and Aqua occurred every 2 days. They were most concentrated in the south and north polar regions and the tropics, while some were scattered in the mid-latitude regions. On the other hand, since MetOp-A and MetOp$\mathrm{B}$ satellites are in mid-morning orbits, the SNOs between MetOp and SNPP occurred roughly every 50 days. Fortunately, once an SNO event occurs, their orbits cross each other in a number of consecutive orbits when satellites fly to the polar regions. Therefore, many SNO observations can be collected during each SNO event. It can be clearly seen in Fig. 2b, showing an enlarged plot of Fig. 2a for a SNO case between CrIS and IASI/B on 1 March 2013.

An example of a SNO event of SNPP and MetOp-A at 18:22 UTC on 27 August 2013 is presented in Fig. 3, where CrIS nadir footprints (indicated by the red circles) and IASI nadir footprints (represented by the blue circles) crossed each other almost at the same time. Since their orbits cross each other at a relatively large angle (see Fig. 3), only measurements in two nadir FORs with smallest scan angles $\left( \pm 1.6^{\circ}\right)$ are extracted for comparison in order to reduce the uncertainties from the orientation of matchup data. CrIS has better 
Table 2. Collocation criteria for CrIS-AIRS and CrIS-IASI SNOs.

\begin{tabular}{ll}
\hline Condition & Criteria \\
\hline FOV distance & CrIS and IASI: $\leq 6.5 \mathrm{~km}$ \\
& CrIS and AIRS: $\leq 6.875 \mathrm{~km}$ \\
Time difference & $\leq 2$ min for high-latitude SNOs \\
& $\leq 15$ min for low-latitude SNOs \\
& between CrIS and AIRS \\
View angle differ- & abs(cos(zen1)-cos(zen2)) $\leq 0.01^{*}$ \\
ences & \\
FOV homogeneity & STDDEV(VIIRS_M16)/MEAN \\
& (VIIRS_M16) $<5 \%$
\end{tabular}

* zen 1 and zen 2 are the zenith angles of paired FOVs from two instruments.

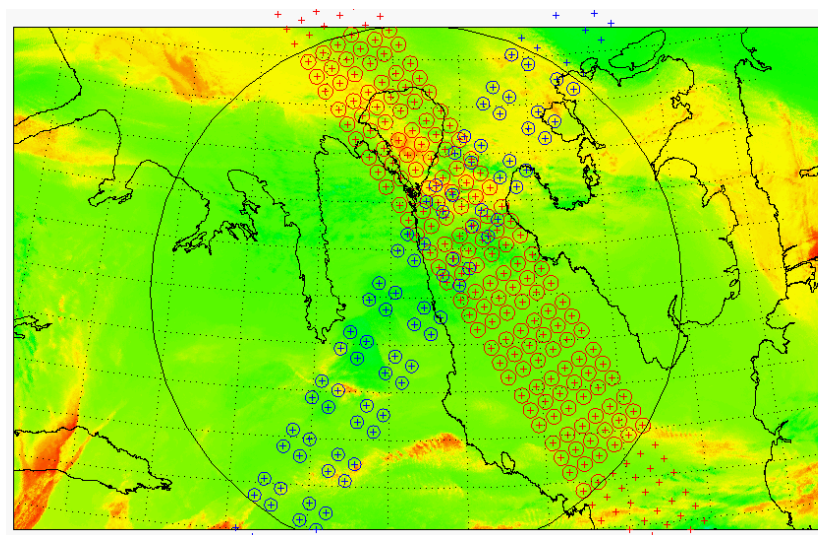

Figure 3. An example of a SNO event of SNPP and MetOp-A at 18:22:22 UTC on 27 August 2013. The blue circles indicate the IASI FOVs and the red ones denote CrIS FOVs at nadir view, while the big black circle indicates the searchable range for CrIS and IASI SNO measurements. The VIIRS image at M16 band is superimposed as the background, where BTs range from 190 (black) to $290 \mathrm{~K}$ (red). CrIS and IASI orbits crossed each other near the region of north Canada.

spatial coverage than IASI. Accordingly, two SNO cases between AIRS on Aqua and CrIS on SNPP are given in Fig. 4, including the polar SNO case occurring at 21:49 UTC and the tropical SNO case at 16:15 UTC on 30 August 2013. Different from the CrIS-IASI SNO case, the SNPP and Aqua orbits follow each other. Therefore, large parts of their swaths overlapped, while the CrIS swath is wider than AIRS. As a result, a different strategy is used to collocate CrIS-AIRS measurements. First, CrIS measurements falling in two nadir FORs are extracted. In the following steps, AIRS pixels that are overlapped with these nadir CrIS measurements are searched by checking collocation criteria. Finally, CrIS and AIRS spectra are paired together for comparison.

Table 2 summarizes the threshold values used for spatial collocation of CrIS and AIRS/IASI FOVs. In order to collocate CrIS FOVs with AIRS and IASI FOVs, we assume that (1) the FOVs of AIRS, CrIS, and IASI are approximately cir- a)

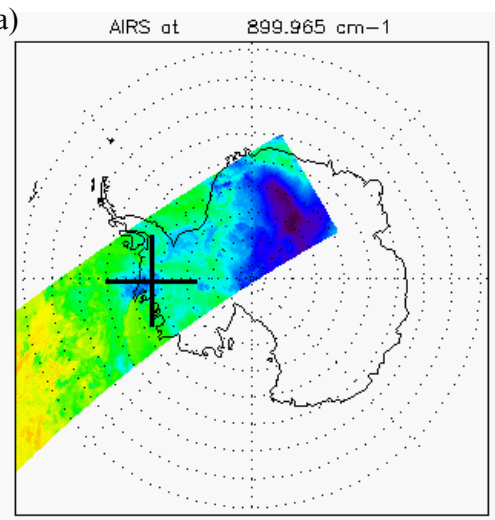

Crls at $\quad 900.000 \mathrm{~cm}-1$
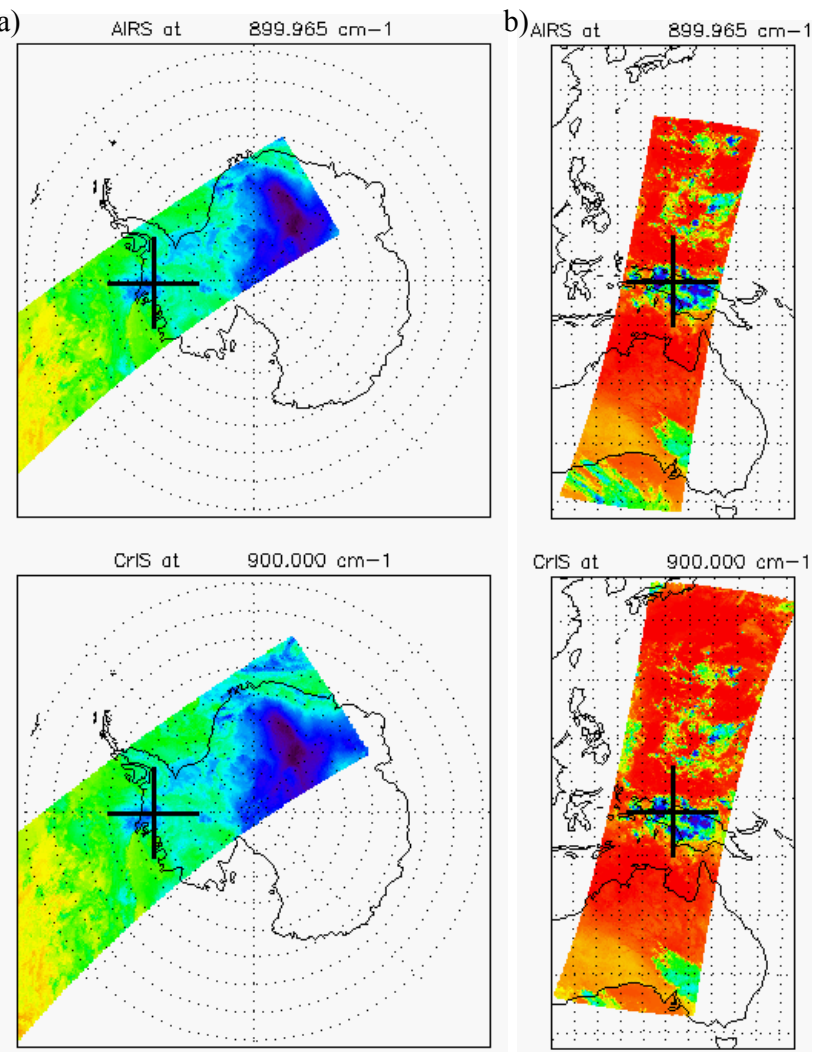

Figure 4. AIRS (top ) and CrIS (bottom) images at $900.0 \mathrm{~cm}^{-1}$ for the polar $((\mathbf{a}))$ and tropical SNO $((\mathbf{b}))$ case, which occurred at 21:49 and 16:15 UTC on 30 August 2013, respectively. The black plus symbols indicate their orbital crossing positions. The BT values range from 185 (black) to $305 \mathrm{~K}$ (red).

cular at nadir, (2) the spatial response is uniformly distributed within the FOVs, and (3) there is no variation of the spatial response between the different channels (e.g., from longwave channels to short-wave channels). Note that in reality, the AIRS FOVs were trimmed on both sides by the blinds attached to the AIRS FOV to avoid overlapping effects between neighboring footprints (Schreier et al., 2010).

Considering their different spatial size of FOVs at nadir - $12.0 \mathrm{~km}$ for IASI, $13.5 \mathrm{~km}$ for AIRS, and $14.0 \mathrm{~km}$ for CrIS - we use the distance between two FOVs to pair overlapped FOVs for CrIS and AIRS/IASI. Specifically, a threshold value of $6.5 \mathrm{~km}$ is used for CrIS and IASI and $6.875 \mathrm{~km}$ is used for CrIS and AIRS. In addition, the observational time and view angle differences (see Table 2 for the specific values) are further examined to filter out the data. Note that the time difference threshold is increased to $15 \mathrm{~min}$ for the AIRS-CrIS tropical SNOs because of their large time differences (Uprety et al., 2013).

Finally, for a typical interferometer like CrIS or IASI, instrument FOV geometry (including beam divergence introduced by finite FOV and off-axis effects caused by its position on a focal plane) and instrument imperfections (such 


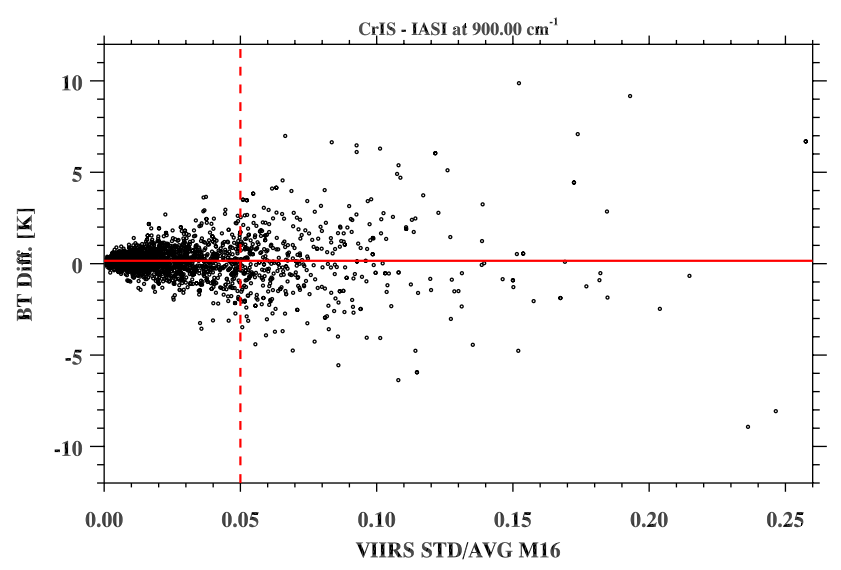

Figure 5. BT difference at $900 \mathrm{~cm}^{-1}$ between CrIS and IASI/B vs. the standard deviation to mean ratio of the VIIRS radiances in band M16. The horizontal line indicates the mean of CrIS-IASI BT differences with a value of $0.158 \mathrm{~K}$ and the standard deviation of BT differences is $1.34 \mathrm{~K}$.

as various optical, mechanical, and electrical imperfections of the interferometer system during the sweep of the optical path difference) impose an apodization function on its interferogram or the so-called self-apodization. The self apodization of the interferogram results in an instrument line shape (ILS) that is shifted and stretched in frequency as well as an amplitude reduction, which has been corrected for CrIS and IASI spectra. However, radiance nonuniformity within the instrument's FOV also affects the ILS associated with each true wavenumber, which has not been taken into account in CrIS and IASI radiance products (Genest and Tremblay, 1999; Tobin et al., 2009). Moreover, inhomogeneous scenes can introduce spatial collocation uncertainties owing to the different point spread functions of CrIS and IASI/AIRS. To avoid these uncertainties, only uniform scenes are selected. We use the collocated Visible Infrared Imaging Radiometer Suite (VIIRS) pixels to check CrIS-AIRS/IASI collocated scene homogeneity by examining the standard deviation to the mean ratio of the VIIRS band M16 (with a central wavelength of $11.8 \mu \mathrm{m}$ ) radiances from the pixels falling in corresponding CrIS FOVs (Wang et al., 2013). On-board the same satellite platform, VIIRS is a whisk-broom scanning imaging radiometer, collecting visible and infrared imagery of the Earth through 22 spectral bands between 0.412 and $12.01 \mu \mathrm{m}$. These bands include 16 moderate resolution bands (M-bands) with a spatial resolution of $750 \mathrm{~m}$ at nadir, five imaging resolution bands (I-bands) with a $375 \mathrm{~m}$ at spatial resolution nadir, and one panchromatic day-night band (DNB) with a $750 \mathrm{~m}$ spatial resolution throughout the scan. VIIRS has four bands that are fully overlapped with CrIS, that is M13 $(4.07 \mu \mathrm{m})$, M15 $(10.7 \mu \mathrm{m})$, M16 $(11.8 \mu \mathrm{m})$ and I5 $(11.45 \mu \mathrm{m})$. Intercomparison between CrIS and VIIRS indicates good agreement between M16 and CrIS (Wang et al., 2012) and therefore VIIRS
M16 band is used to characterize the CrIS scene uniformity. Specifically, scene uniformity of a circular area centered at CrIS FOVs with a radius of $14 \mathrm{~km}$ is checked. The area basically includes both collocated CrIS and IASI or AIRS FOVs and actually is the environment surrounding the collocated measurements. A spatially uniform environment surrounding the collocated measurements is desirable to compensate for minor violations of collocation and coincidental criteria as well as to reduce the uncertainties caused by navigation errors. Furthermore, it avoids a potential threat of nonuniform features (e.g., moving clouds) to the collocation. Demonstrated in Fig. 5 is the BT difference between CrIS and IASI/B at $900 \mathrm{~cm}^{-1}$ vs. the standard deviation to mean ratio of the VIIRS radiances in band M16. It shows that with a larger ratio, the spread of the BT difference becomes larger, whereas the BT differences converge when the ratio values decrease. From a practical point of view, this ratio is an effective method to constrain scene homogeneity to reduce the comparison uncertainties, specifically when a smaller value is chosen.

Similar sensitivity tests have been performed to check how the relaxed collocation criteria affect the BT differences. It is found that the FOV distance and collocation environment uniformity are the major factors that control the scattering pattern of BT differences and sample number, while time differences have small effects. For CrIS and IASI SNOs, since only observations in two nadir FORs are used, all the samples meet the threshold of angle differences. On the other hand, for CrIS and AIRS SNOs, in order to meet the angle difference threshold, the CrIS FOVs' satellite zenith angles are in the range of $0.6-3.36^{\circ}$ while the collocated AIRS FOVs' zenith angles range from 0.5 to $8.0^{\circ}$. In conclusion, constricting collocation criteria reduces both the sample size and the scattering of BT differences. However, as shown later, we still have enough samples to cover the instrument dynamic range.

Figure 6 gives the mean spectra of paired CrIS and IASI SNO FOVs for the SNO event shown in Fig. 3. During this SNO event, CrIS on SNPP was operated in the FSR mode. Accordingly, CrIS spectra are collocated at the full resolution mode, indicated by red lines (Chen et al., 2014). The full resolution spectra can be further processed to be the normal mode data (like current officially released CrIS SDR data) by the ADL software, which are represented by blue lines in Fig. 6. In order to clearly show the agreement between CrIS and IASI, an enlarged plot is given in Fig. $6 \mathrm{~b}$ at the spectral range from 2200 to $2400 \mathrm{~cm}^{-1}$. However, in order to quantify the detailed differences between them, we need to convert CrIS and IASI onto common spectral grids, which are discussed below. 

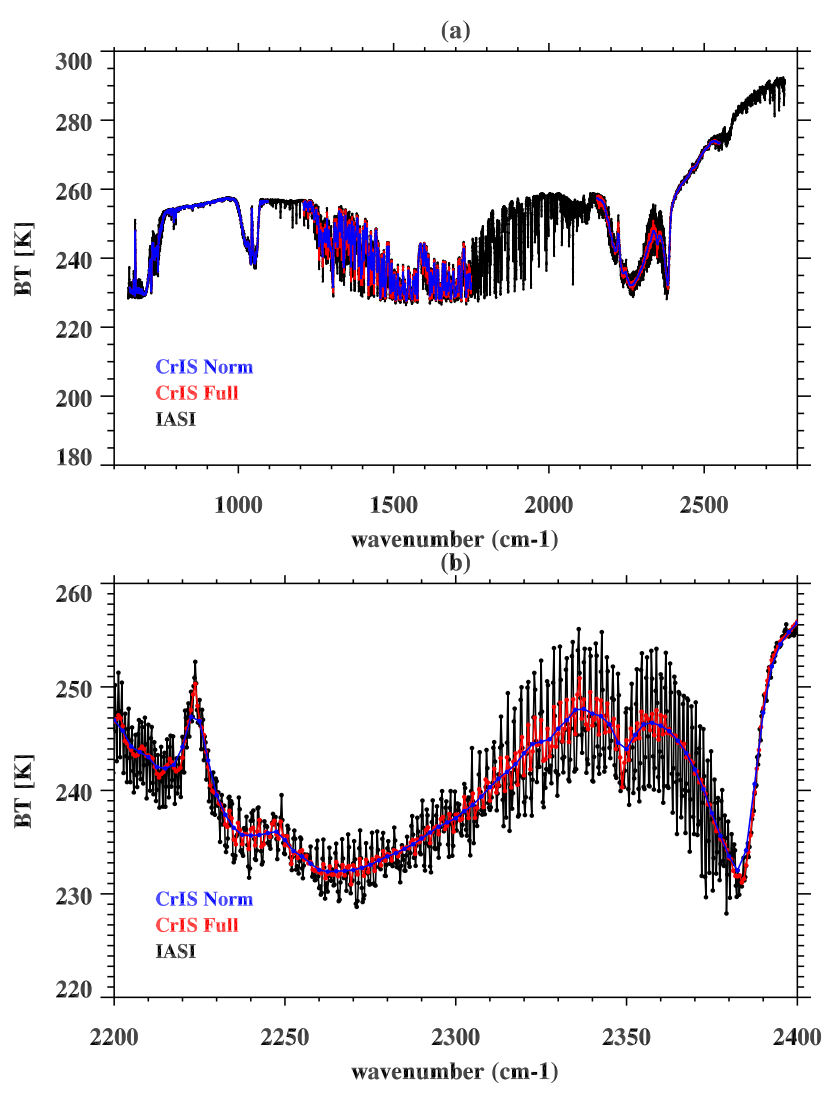

Figure 6. (a) CrIS and IASI spectra for paired CrIS and IASI SNO FOVs on 27 August 2013 and (b) enlarged plot at the spectral range from 2200 to $2400 \mathrm{~cm}^{-1}$.

\subsection{Spectral match}

This part describes the method of how to convert paired CrIS-IASI and CrIS-AIRS spectra onto common spectral grids in order to quantify their radiometric differences.

\subsubsection{CrIS vs. IASI}

Both CrIS and IASI are Fourier transform infrared (FTIR) spectrometers. Given that IASI has a longer optical path difference (OPD) $(2.0 \mathrm{~cm}$ for all three bands) than CrIS $(0.8 \mathrm{~cm}$ for LWIR band, 0.4 for MWIR band, and 0.2 for SWIR band), high spectral resolution IASI spectra are converted into low spectral resolution CrIS spectra for intercomparison. As a result, some fine spectral structures shown in IASI spectra are smoothed out by this procedure. Specifically, five steps are performed, including: (1) converting IASI spectra to interferograms using Fourier transform; (2) de-apodizing IASI interferograms using IASI apodization functions; (3) truncating the IASI interferograms based on CrIS OPD specification; (4) apodizing truncated interferograms using CrIS Hanning apodization functions; and (5) transforming interferograms back into spectra using inverse Fourier transform.

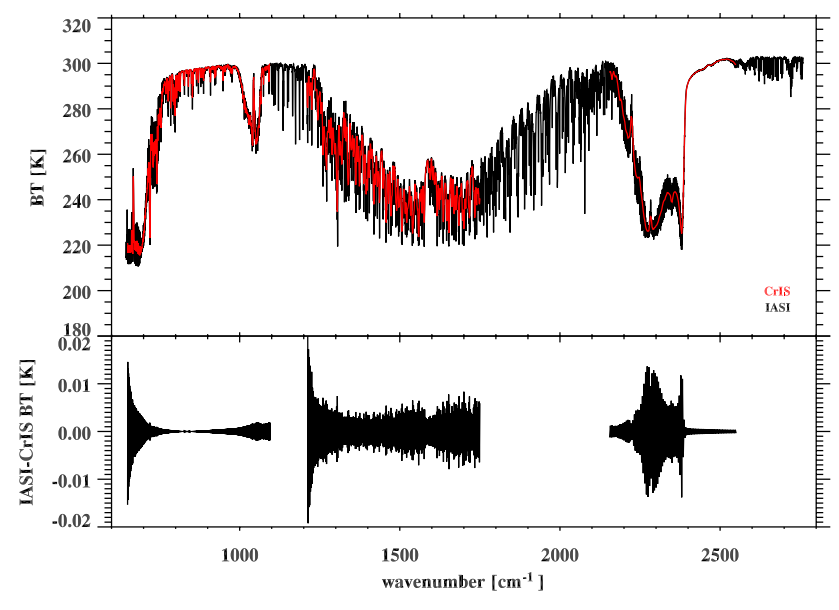

Figure 7. Top: CrIS (red) and IASI (black) spectra simulated by LBLRTM using an identical atmospheric profile as an input. Bottom: their spectral differences. CrIS and IASI spectra are shown in their own spectral sampling resolution after apodization. Their BT differences are computed at the CrIS spectral grids by converting the IASI spectrum onto the CrIS spectral grids.

Shown in Fig. 7a are CrIS and IASI spectra simulated by LBLRTM using an identical atmospheric profile as input. Theoretically, these two spectra represent the identical Earth and atmospheric spectra but are sampled at the different spectral grid. When one resamples the IASI spectrum onto the CrIS spectral grids, if the conversion method is perfect, it is expected that the spectral differences of these two spectra are close to zero with negligible differences. Figure $7 b$ gives the spectral differences between the CrIS spectrum and IASI spectrum that are converted onto CrIS spectral grids. This is computed by converting the radiance spectra into brightness temperature (BT) spectra by using Planck function and then calculating the differences. Their BT spectral differences show the ringing patterns (jumping up and down) with the zero mean due to nonperfection of the conversation method. For most spectral channels, the BT differences are less than in the range from -0.01 to $0.01 \mathrm{~K}$. At the edge channels in LWIR and MWIR bands and $2300-2400 \mathrm{~cm}^{-1}$ spectral regions in SWIR bands, the resampling errors are in the range of $[-0.02,0.02 \mathrm{~K}]$. Therefore, it suggests that the method is very accurate with negligible uncertainties.

\subsubsection{CrIS vs. AIRS}

For AIRS and CrIS, it is a challenging task to convert AIRS and CrIS onto a common spectral domain. As a grating spectrometer, AIRS spectral resolution varies with different bands, and spectral gaps exist due to the design (see Fig. 1). Moreover, the observations from some channels are not of good quality due to the bad or degraded detectors (the channel property list can be found at http://disc.sci.gsfc.nasa. gov/AIRS/documentation/v5_docs). To the date when this manuscript was finalized, 274 of 2378 AIRS channels are 
Table 3. Statistics of CrIS-AIRS BT differences at 25 spectral regions.

\begin{tabular}{|c|c|c|c|c|c|c|c|c|c|}
\hline & \multirow{2}{*}{$\begin{array}{r}\text { Spectral range } \\
\left(\mathrm{cm}^{-1}\right)\end{array}$} & \multicolumn{2}{|c|}{ North SNOs } & \multicolumn{2}{|c|}{ South SNOs } & \multicolumn{2}{|c|}{ Tropical SNOs } & \multicolumn{2}{|c|}{ Global } \\
\hline & & $\begin{array}{r}\text { Mean } \\
(\mathrm{K})\end{array}$ & $\begin{array}{l}\text { SD } \\
(\mathrm{K})\end{array}$ & $\begin{array}{r}\text { Mean } \\
(\mathrm{K})\end{array}$ & $\begin{array}{l}\text { SD } \\
(K)\end{array}$ & $\begin{array}{r}\text { Mean } \\
(\mathrm{K})\end{array}$ & $\begin{array}{l}\text { SD } \\
(K)\end{array}$ & $\begin{array}{r}\text { Mean } \\
(\mathrm{K})\end{array}$ & $\begin{array}{l}\text { SD } \\
(K)\end{array}$ \\
\hline 1 & $650.000-681.875$ & 0.1025 & 0.0432 & 0.0538 & 0.0300 & 0.0261 & 0.0265 & 0.0500 & 0.0443 \\
\hline 2 & $690.000-710.000$ & 0.1661 & 0.0642 & 0.1201 & 0.0751 & 0.1572 & 0.0227 & 0.1509 & 0.0528 \\
\hline 3 & $733.500-755.000$ & -0.0297 & 0.1292 & -0.0348 & 0.0921 & 0.1088 & 0.0854 & 0.0444 & 0.1210 \\
\hline 4 & $760.000-781.750$ & -0.0215 & 0.1674 & -0.0045 & 0.0980 & 0.1180 & 0.1292 & 0.0581 & 0.1482 \\
\hline 5 & $800.000-830.000$ & 0.0006 & 0.1725 & 0.0192 & 0.1044 & 0.1688 & 0.1452 & 0.0962 & 0.1645 \\
\hline 6 & $830.000-849.000$ & -0.0526 & 0.1781 & -0.0384 & 0.1116 & 0.1072 & 0.1502 & 0.0374 & 0.1678 \\
\hline 7 & $860.000-887.000$ & -0.0318 & 0.1822 & -0.0244 & 0.1106 & 0.0910 & 0.1470 & 0.0366 & 0.1601 \\
\hline 8 & 889.000-903.000 & -0.0209 & 0.1803 & -0.0104 & 0.1138 & 0.1382 & 0.1536 & 0.0679 & 0.1705 \\
\hline 9 & $911.250-941.250$ & -0.0304 & 0.1849 & -0.0247 & 0.1125 & 0.1280 & 0.1509 & 0.0570 & 0.1705 \\
\hline 10 & $941.250-973.750$ & 0.0136 & 0.1859 & 0.0241 & 0.1172 & 0.1265 & 0.1470 & 0.0773 & 0.1601 \\
\hline 11 & $977.375-1010.00$ & -0.0008 & 0.1856 & 0.0794 & 0.1212 & 0.0124 & 0.1396 & 0.0245 & 0.1506 \\
\hline 12 & $1075.00-1095.00$ & -0.1614 & 0.2092 & -0.1455 & 0.1725 & -0.0210 & 0.1474 & -0.0816 & 0.1815 \\
\hline 13 & $1240.50-1262.00$ & 0.0477 & 0.1456 & 0.0543 & 0.0816 & 0.1694 & 0.0995 & 0.1153 & 0.1234 \\
\hline 14 & $1285.00-1338.75$ & -0.0145 & 0.1069 & 0.0285 & 0.0697 & 0.0237 & 0.0709 & 0.0160 & 0.0820 \\
\hline 15 & $1355.00-1381.00$ & -0.0679 & 0.0968 & -0.0246 & 0.0806 & -0.0505 & 0.0752 & -0.0486 & 0.0830 \\
\hline 16 & $1380.00-1410.00$ & 0.0031 & 0.0945 & 0.0265 & 0.0804 & 0.0155 & 0.0800 & 0.0151 & 0.0839 \\
\hline 17 & $1415.00-1435.00$ & -0.0127 & 0.0736 & -0.0112 & 0.0617 & 0.0368 & 0.0843 & 0.0145 & 0.0809 \\
\hline 18 & $1461.25-1495.00$ & -0.0701 & 0.0669 & -0.0281 & 0.0571 & -0.0846 & 0.0863 & -0.0685 & 0.0795 \\
\hline 19 & $1561.25-1591.25$ & -0.0857 & 0.0697 & -0.0953 & 0.0418 & -0.0438 & 0.0883 & -0.0651 & 0.0793 \\
\hline 20 & $1591.25-1613.00$ & -0.1649 & 0.1512 & -0.1710 & 0.1545 & -0.0459 & 0.0939 & -0.1017 & 0.1383 \\
\hline 21 & & & & & & & J & 0.2109 & 0.0794 \\
\hline 22 & $2260.00-2285.00$ & & 0.1 & & 0.2986 & & 0.0713 & 0.1869 & 0.2390 \\
\hline 23 & $2310.00-2340.00$ & 0.1168 & 0.2300 & 0.0113 & 0.1591 & -0.1134 & 0.0459 & -0.0321 & 0.1677 \\
\hline 24 & $2360.00-2400.00$ & 0.1827 & 0.1009 & 0.2061 & 0.1010 & 0.1195 & 0.0622 & 0.1537 & 0.0905 \\
\hline 25 & $2447.50-2475.00$ & 0.0110 & 0.1810 & 0.0757 & 0.3196 & 0.0240 & 0.2170 & 0.0327 & 0.2380 \\
\hline
\end{tabular}

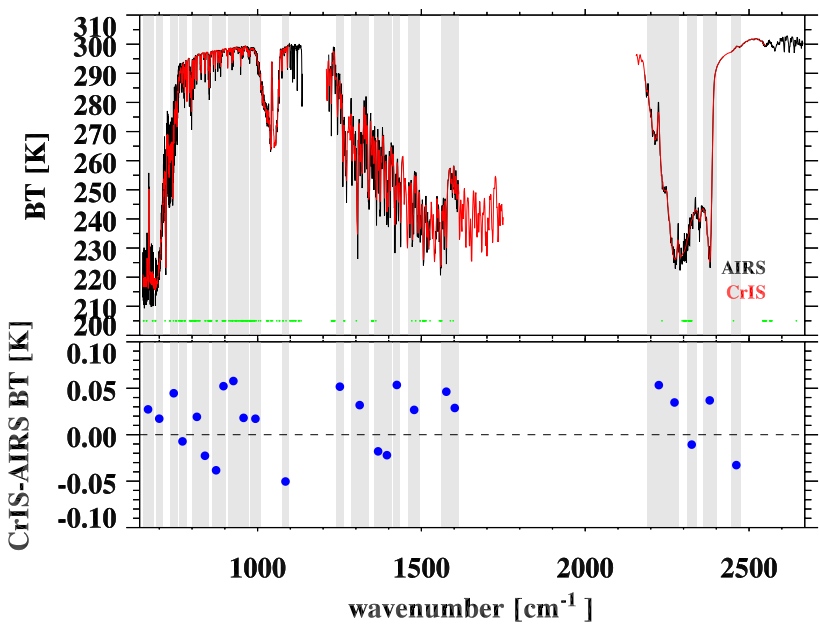

Figure 8. Top: CrIS (black) and AIRS (red) spectra simulated by LBLRTM using an identical atmospheric profile. Bottom: their spectral differences along the 25 spectral regions, indicated by the gray bars. The green dots indicate the AIRS degraded or dead channels.

not recommended for use. Due to the above consideration, the intercomparison between CrIS and AIRS is focused on
25 spectral regions, as shown in the gray bars in Fig. 8 (the spectral range can be found in Table 3). Specifically, the radiance values falling within the each comparison region are averaged together, respectively for CrIS and AIRS spectra. The radiances for AIRS bad channels are linearly interpolated using the values from neighboring channels. The averaged radiance values are then converted into BTs through the mean wavenumber, and their BT differences are computed. While this match method cannot compare AIRS and CrIS at the finest spectral scale like CrIS and IASI, we do believe that this method can minimize the issues due to the difference of AIRS and CrIS instrument design and spectral response, and thus can produce more meaningful assessment of the radiometric differences between CrIS and AIRS. The similar band-average methods are also utilized by Jouglet et al. (2014) who selected 33 spectral regions to compare CrIS with IASI as well as by Tobin et al. (2013b) who selected six spectral regions with a 10 -wavenumber interval to compare CrIS with AIRS. Shown in Fig. 8 are the BT differences between the LBLRTM-simulated AIRS and CrIS spectra using an identical atmospheric profile. A simple average method is used to convert both CrIS and AIRS spectra onto the 25 spectral regions. Among 25 spectral regions, there are seven spectral regions where the magnitude of BT differ- 


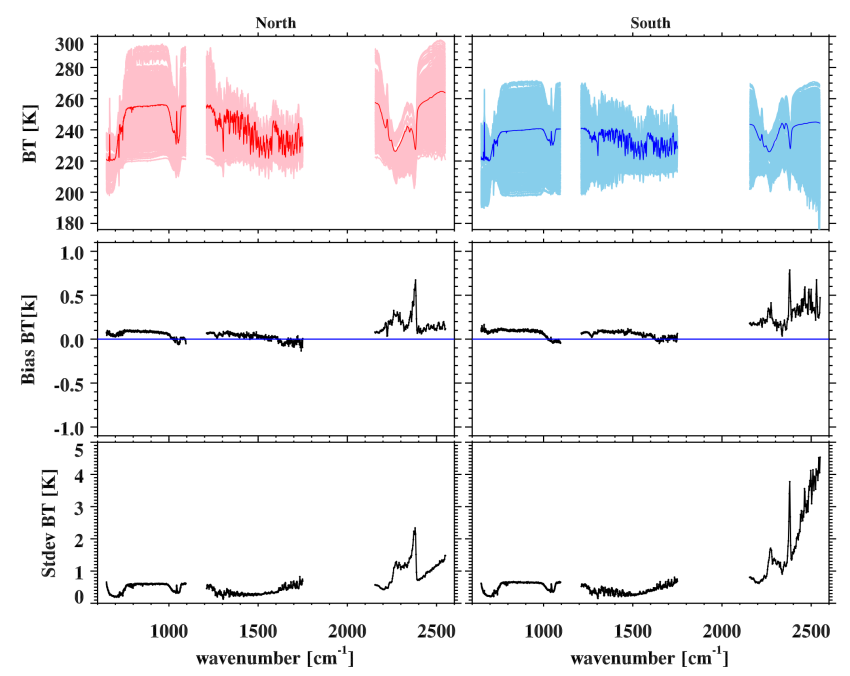

Figure 9. CrIS spectral distribution (top) for CrIS-IASI/A north SNOs (left) and south SNOs (right) and the mean (middle) and standard deviation (bottom) of CrIS-IASI/A BT differences. The solid lines in the top figure represent the average spectrum from all the samples.

ences is less than $0.02 \mathrm{~K}, 12$ spectral regions are in the range of $[0.02,0.05 \mathrm{~K}]$, and six spectral regions are in the range of $[0.05,0.06 \mathrm{~K}]$. Given the fact that there are around 274 ( $11.5 \%$ of 2378 channels) AIRS degraded channels, we think that the uncertainties caused by the spectral match method are at an acceptable level.

\subsection{Data processing}

After the above two steps, the CrIS-AIRS and CrIS-IASI spectra are spatially and spectrally matched together. A whole year of data in 2013 is processed based on the above steps, including CrIS-IASI/A, CrIS-IASI/B, and CrISAIRS. For each pair of sensors, the SNO observations are categorized into the SNO observations at the north polar region (north SNOs), those at the south polar region (south SNOs), and those in the tropics (tropical SNOs, CrIS-AIRS only).

Based on the collocation criteria, a total of 2748 pairs of spectra were collocated for CrIS and IASI-A in 2013, composed of 1274 pairs from north SNOs and 1474 pairs from south SNOs. For CrIS and IASI-B, there are a total of 2008 pairs of the SNO spectra in 2013, categorized as 952 pairs from north SNOs and 1056 pairs from south SNOs, which are fewer than CrIS-IASI/A due to the fact that IASI-B data have been distributed under operational mode since 24 April 2013. Given a sufficient number of collocations, the radiometric noise from each instrument should be canceled out and therefore should not contribute to the mean difference.

For CrIS and AIRS, due to the fact that the two instruments follow each other, each SNO event has hundreds (around 200-600) of collocated spectra that meet the collocation cri-

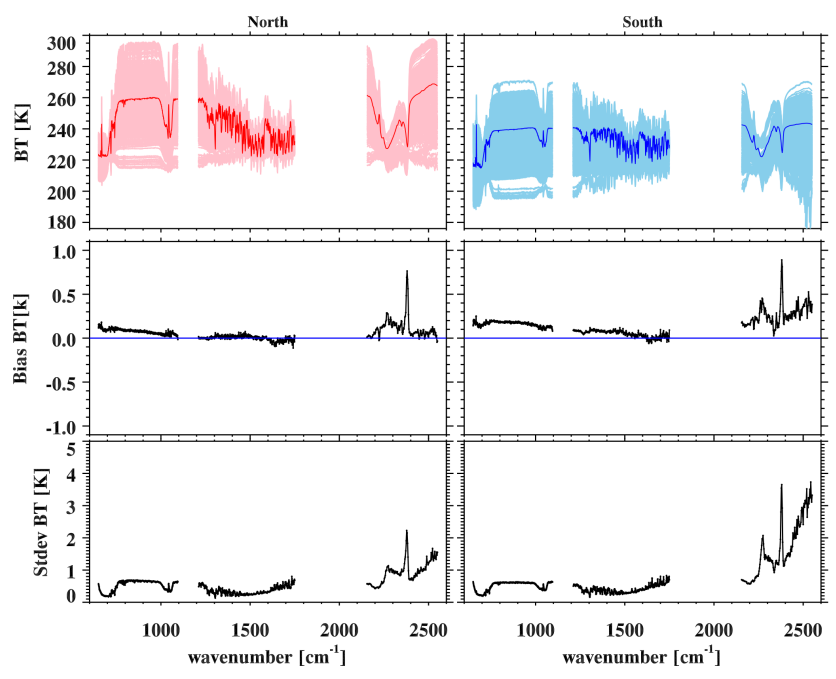

Figure 10. Same as Fig. 9 but for CrIS-IASI/B.

teria. Consequently, the CrIS and AIRS spectra are averaged for each SNO event and then their BT differences are then computed in order to show how their BT differences vary with time. Specifically, there are 324 and 390 SNO events that occurred in the polar regions and the tropics, respectively.

\section{Results and discussion}

\subsection{CrIS vs. IASI}

Figures 9a and 10a show CrIS spectral distribution for CrISIASI/A and CrIS-IASI/B SNO observations, where the red lines indicate the observations for north SNOs and the blue lines represent those for south SNOs. If one examines the spectra at the atmospheric window regions $\left(850-900 \mathrm{~cm}^{-1}\right)$, the BT values range from 220 to $295 \mathrm{~K}$ in north SNOs, while they range from 190 to $270 \mathrm{~K}$ in south SNOs. Especially, from 04:00 to 05:30 UTC on 3 August 2013 near the north of middle Siberia $\left(94^{\circ} \mathrm{E}, 72^{\circ} \mathrm{N}\right)$, there are 16 samples whose $\mathrm{BT}$ values at atmospheric windows regions are larger than $290 \mathrm{~K}$. This suggests that CrIS-IASI SNO observations have a relatively large dynamic range for both CrIS-IASI/A and CrIS-IASI/B SNO samples. The mean and standard deviation of BT differences of CrIS-IASI/A are given in Fig. 9b, while those from CrIS-IASI/B are shown in Fig. 10b. At LWIR and MWIR bands, CrIS agrees well with IASI and the BT differences are less than $0.2 \mathrm{~K}$, while the standard deviation ranges from 0.2 to $0.7 \mathrm{~K}$ dependent on different spectral absorption regions. Compared with both IASI/A and IASI/B, CrIS is slightly warmer than IASI (less than $0.2 \mathrm{~K}$ ) at most spectral regions. However, at SWIR band, the BT differences range from 0.2 to $1.0 \mathrm{~K}$ and the standard deviation also increases, especially for the south SNOs. It is not surprising that BT differences are larger at the SWIR band because the radiance values in SWIR are much smaller than LWIR and 


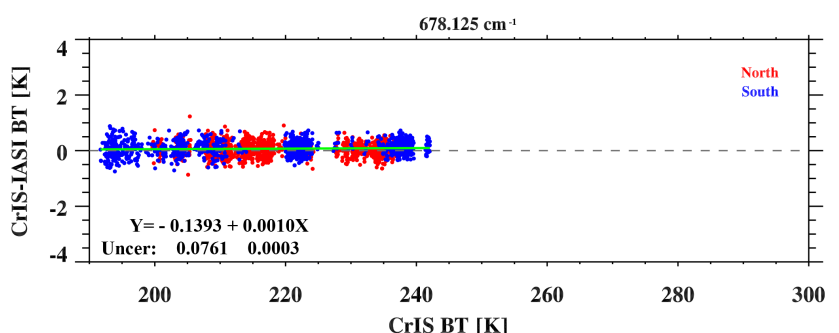

$900.000 \mathrm{~cm}^{-1}$
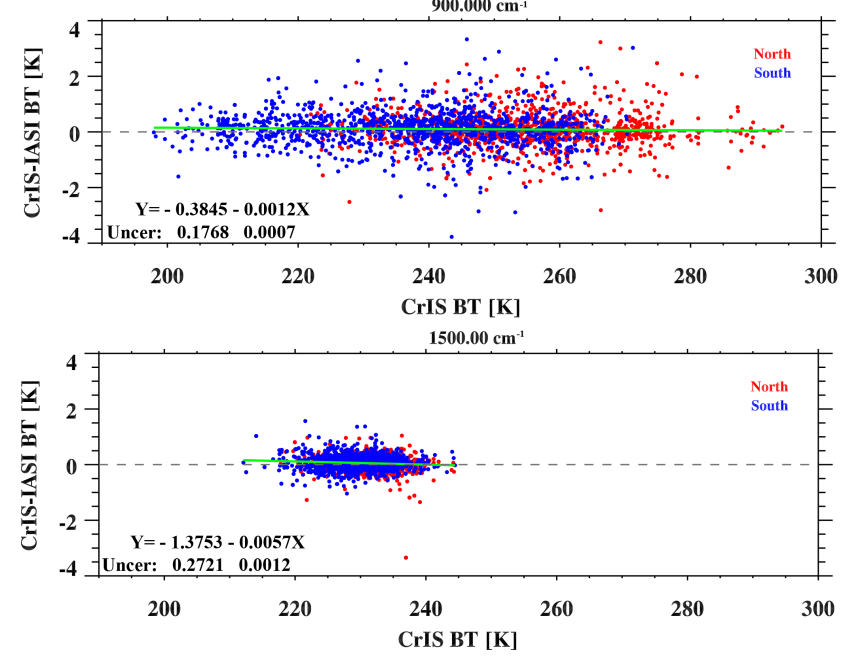

Figure 11. Scatter plots of CrIS-IASI/A BT differences vs. CrIS BT at $678.125,900.0$, and $1500 \mathrm{~cm}^{-1}$. The red and blue dots represent the data from north and south SNOs and the green line is the linear regression line. The regression results and their $1 \sigma$ uncertainties are also listed.

MWIR bands given the same BT values. The explanation of the large standard deviation probably is due to the decreasing radiance value at the short-wave band for cold scenes for both CrIS and IASI. When one examines the mean BT differences of CrIS-IASI, a considerable sharp increase can be found at spectral line transition region (around $2400 \mathrm{~cm}^{-1}$ ), which are shown in both Figs. 9b and 10b. It is probably caused by two reasons. First, given a relatively large spectral resolution of $2.5 \mathrm{~cm}^{-1}$ for the CrIS SWIR band, it is challenging to achieve the same spectral accuracy as the LWIR and SWIR bands (Strow et al., 2013b). Therefore, the spectral calibration for SWIR band is not as good as LWIR and MWIR bands. Secondly, it is speculated that there is a small nonlinear response for the detectors in SWIR band, which currently are treated as linear detectors and there is no nonlinear correction for the CrIS SWIR band (D. Tobin, University of Wisconsin, personal communication, 2013). However, the investigations are not conclusive at this point and the root cause is still under investigation.

When one carefully compares CrIS-IASI/A and CrISIASI/B results, especially for results of the south SNO samples, we can find that CrIS-IASI/A and CrIS-IASI/B are slightly different. If one treats CrIS as a transfer radiometer
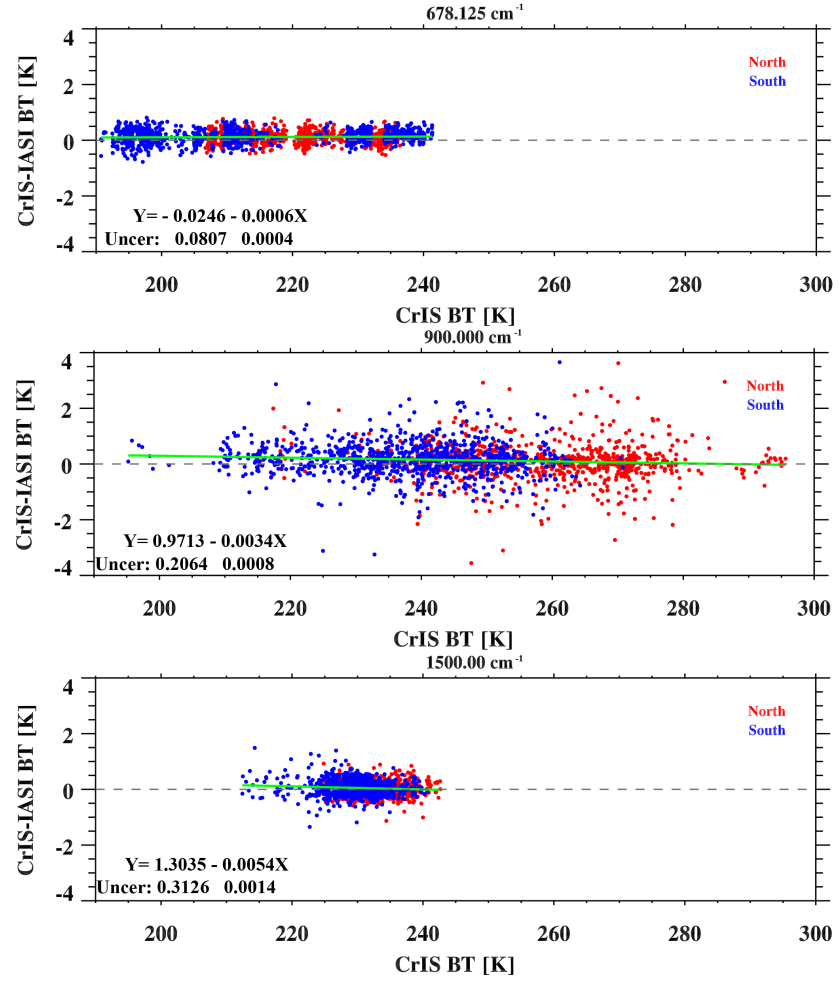

Figure 12. Same as Fig. 11 but for CrIS-IASI/B.

and then CrIS measurements are assumed to be canceled out, the double differences of CrIS-IASI/B and CrIS-IASI/A indicate that IASI/B is slightly warmer (less than $0.1 \mathrm{~K}$ ) than IASI/A in LWIR bands and they are well consistent with each other in MWIR bands. The observed differences between IASI-A and IASI-B in the long-wave band are suspected to be due to the differences of instruments' nonlinearity corrections. This result agrees well with the findings by D. Jouglet from CNES (Jouglet et al., 2014), who directly compared IASI/A and IASI/B spectra with $50 \mathrm{~min}$ difference. However, the double difference results should be carefully interpreted because two data sets were collected in different time periods and the bias from the transfer radiometer CrIS may not be totally canceled out.

In order to show how the BT differences are dependent on scene temperatures, scatter plots of CrIS-IASI BT differences vs. CrIS BTs at three individual channels (including one $\mathrm{CO}_{2}$ absorption channel, one long-wave window channel, and one water vapor channel) are shown in Fig. 11 for CrIS-IASI/A and in Fig. 12 for CrIS-IASI/B, correspondingly. Specifically, the red dots indicate the observations from north SNOs and the blue dots represent those from south SNOs, while the green lines give the linear fitting line. For all three individual channels, the slope of linear regression is very small albeit statistically significant, indicating that there are no strong scene-dependent features. This also applies to the BT differences between CrIS and 

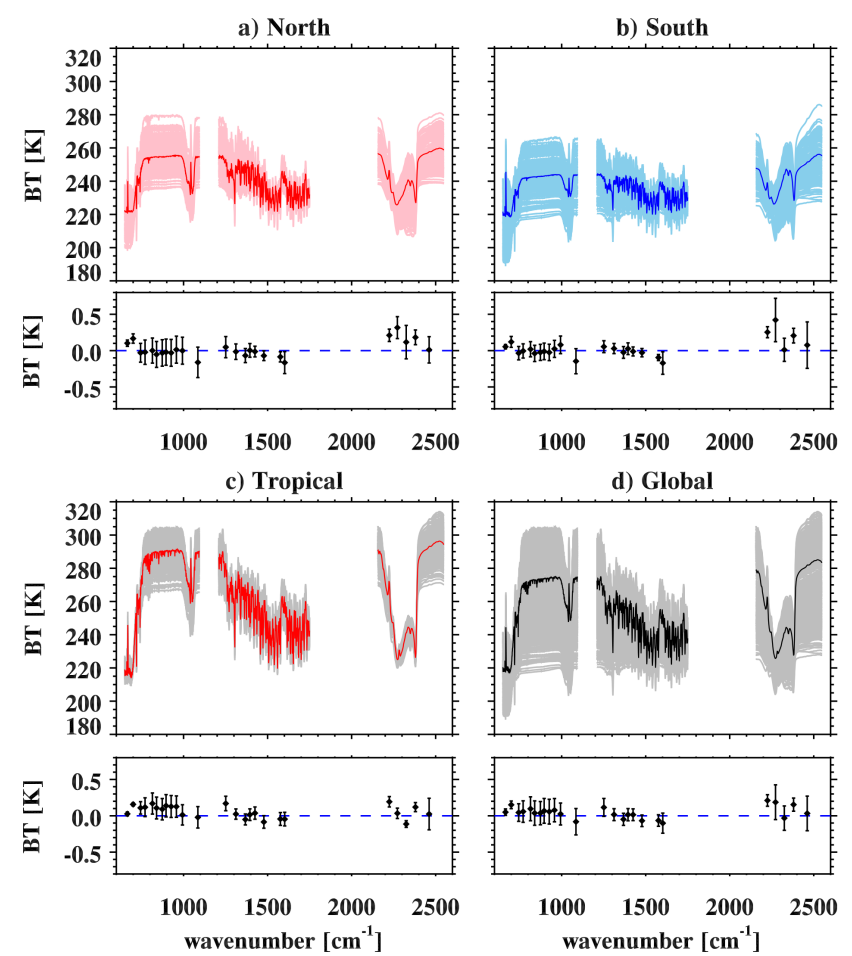

Figure 13. CrIS spectral distribution for CrIS-AIRS SNOs and their mean BT differences with the standard deviation along the $25 \mathrm{spec}-$ tral regions, including (a) north SNOs, (b) south SNOs, (c) tropical SNOs, and (d) the global data set that combines three data sets together. The solid lines represent the average spectrum from the samples.

IASI/B, shown in Fig. 12. However, it is necessary to point out that CrIS-IASI comparison is only limited to relatively cold scenes in the polar regions and the comprehensive assessment of CrIS-IASI radiometric consistency still needs to be extended to the low-latitude regions in the future.

\subsection{CrIS vs. AIRS}

The CrIS-AIRS SNO comparison results are shown in Fig. 13, including CrIS spectral distribution and the mean and standard deviation of CrIS-AIRS BT difference. They are categorized into north, south, and tropical SNOs and the global data set that combines all three SNO data sets together. In addition, the statistics of CrIS-AIRS BT differences along the 25 spectral regions are summarized in Table 3 . The SNO spectral distribution clearly shows the characteristic in different climate regions if one visually inspects the dynamic range of the BT values at the atmospheric window region. In other words, the BTs from tropical SNOs (ranging from 265 to $310 \mathrm{~K}$ ) are different from polar SNOs (ranging from 210 to $280 \mathrm{~K}$ ). The following findings are revealed based on Fig. 13 and Table 3. First, at the $650-681.875 \mathrm{~cm}^{-1}$ and 690 $710 \mathrm{~cm}^{-1}$ spectral regions in LWIR band, CrIS is warmer than AIRS for all three SNO data sets and the BT differences range from 0.026 to $0.167 \mathrm{~K}$. At the other 10 spectral regions (spectral region 3-11 and 12 in Table 3) in LWIR band, CrIS and AIRS agree well and the BT differences are less than $0.1 \mathrm{~K}$ for north and south SNOs; however, CrIS is warmer than AIRS by $\sim 0.1 \mathrm{~K}$ for tropical SNOs. At the ozone absorption region of $1075-1095 \mathrm{~cm}^{-1}$ in LWIR band, CrIS is slightly colder than AIRS and the BT differences range from -0.02 to $-0.161 \mathrm{~K}$. Second, among six of eight spectral regions (spectral region 14-19 in Table 3) in the MWIR band, CrIS-AIRS BT differences are less than or around $0.1 \mathrm{~K}$ for all three SNO data sets. Only at the 1240.50-1262.00 and $1591.25-1613.00 \mathrm{~cm}^{-1}$ spectral regions, are BT differences larger than $0.15 \mathrm{~K}$ in some SNO data sets. Finally, in the SWIR band, CrIS is warmer than AIRS from 0.01 to $0.42 \mathrm{~K}$ for south and north SNOs but their agreement is much better for tropical SNOs. To combine the three SNO data sets together, Fig. 13 and Table 3 also summarize the global CrISAIRS BT difference statistics. Generally speaking, among 21 of 25 comparison spectral regions, the CrIS-AIRS BT differences are less than or around $0.1 \mathrm{~K}$; in the remaining four spectral regions (one in the LWIR band and three in the SWIR band), the BT differences range from 0.15 to $0.21 \mathrm{~K}$. Moreover, among 16 of 25 spectral regions, CrIS is slightly warmer than AIRS.

Given the fact that each SNO data set has its own unique BT distribution, it is possible to check their BT differences vs. scene BTs with a relatively large dynamic range. Four spectral regions are selected, including the $\mathrm{CO}_{2}$ absorption region $\left(650-681.88 \mathrm{~cm}^{-1}\right)$, the atmospheric window region (889-903 $\left.\mathrm{cm}^{-1}\right)$, the water vapor absorption region $(1380$ $\left.1410 \mathrm{~cm}^{-1}\right)$, and the short-wave region $\left(2190-2260 \mathrm{~cm}^{-1}\right)$. Finally, the three SNO data sets can be simple combined together to derive the global statistics. Figure 14 gives CrISAIRS BT differences varying with CrIS BTs, where the red, blue, and black dots indicate the data from north, south, and tropical SNOs, respectively. Specifically, the BT differences at the $\mathrm{CO}_{2}$ absorption, water vapor absorption band shortwave regions show weak scene-dependent features. At the atmospheric window region, there is no scene-dependent feature for polar SNOs (range from 210 to $270 \mathrm{~K}$ ), but the BT difference increase with the scene BTs for tropical SNOs when BTs are larger than $270 \mathrm{~K}$. These features can be clearly revealed by the regression line shown in Fig. 14. One explanation of these scene-dependent features can be due to the imperfection of the instrument's nonlinearity correction. For AIRS and CrIS instrument, nonlinearity correction has been performed during radiometric calibration to correct the nonlinear response for the instrument detectors (Pagano et al., 2003; Tobin et al., 2013b). The deficiency of nonlinearity correction for one or both of instruments can result in this kind of scene-dependent pattern based on the previous study (Tobin et al., 2013b). Figure 15 shows the AIRS-CrIS BT difference time series at the four spectral regions. The BT difference time series from polar SNOs show weak seasonal variations with magnitude of $0.05 \mathrm{~K}$ in the water vapor 

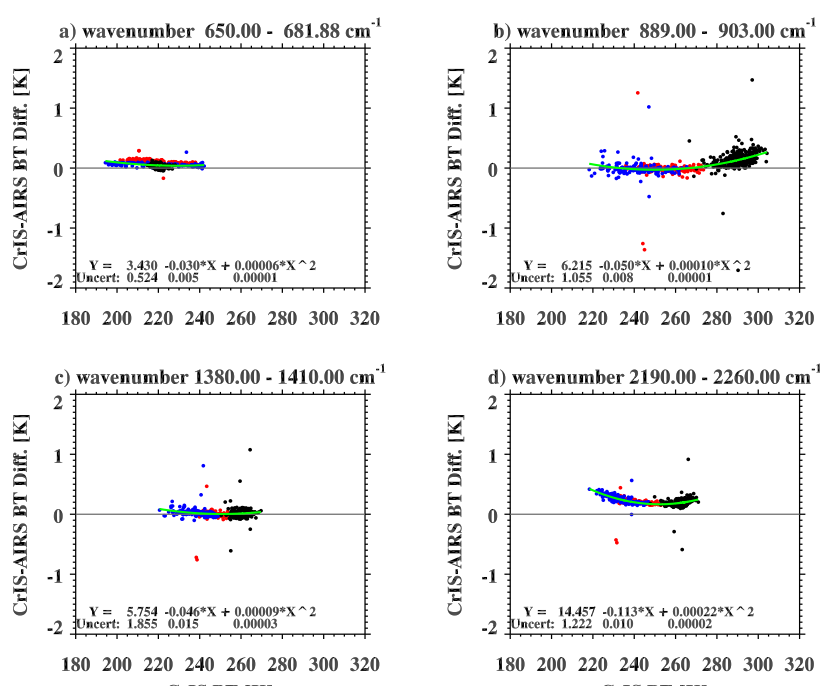

CrIS BT [K]

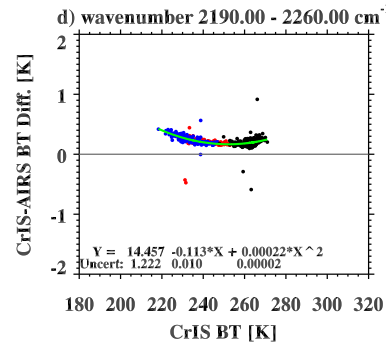

Figure 14. Scatter plots of CrIS-AIRS BT differences vs. CrIS BT at four spectral regions: (a) $650-681.88 \mathrm{~cm}^{-1}$, (b) $889-903 \mathrm{~cm}^{-1}$, (c) $1380.0-1410.00 \mathrm{~cm}^{-1}$, and (d) $2190-2260 \mathrm{~cm}^{-1}$. The red, blue, and black dots indicate the BT differences from north SNOs, south SNOs, and tropical SNOs. The quadratic regressions are shown in green. The regression results and their $1 \sigma$ uncertainties are also listed.

absorption regions, $0.1 \mathrm{~K}$ in the $\mathrm{CO}_{2}$ absorption region, and $0.15 \mathrm{~K}$ in the short-wave regions. This can be explained by the scene-dependent BT difference features shown in Fig. 14. In other time series of the BT differences, there is no apparent seasonal variation and there are no long-term trends.

\subsection{Discussion}

Due the fact that both CrIS and AIRS are on afternoon orbits, one of the advantages is that the CrIS-AIRS intercomparison can be performed globally. On the other hand, however, because of different instrument characteristics (grating spectrometer vs. interferometer), it is very hard to compare them at the finest spectral scale. Consequently, a simply average method is carried out through several boxcar-passed spectral regions. This method has been used by different groups. While the results indicate that CrIS and AIRS have small radiometric differences, it very difficult to compare them because these comparisons are performed at different comparison spectral regions. We suggest that another round of CrIS and AIRS intercomparison should be planned by choosing common comparison spectral regions by different groups in order to further advance our understanding on their radiometric differences.

For CrIS and IASI intercomparison, the results from different group are consistent with each other. Specifically, while different collocation methods and criteria are used, this study and the one by Tobin et al. (2013a, b) both identify the large BT differences at the spectral transition region of about
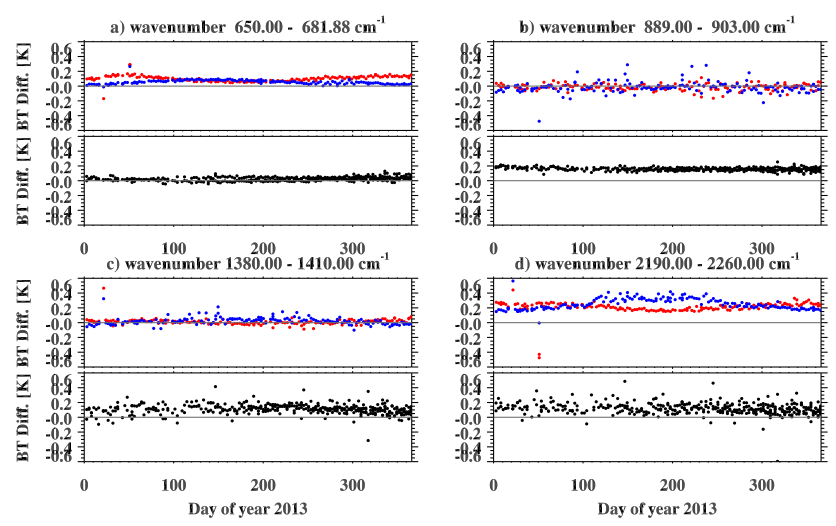

Figure 15. Time series of CrIS-AIRS BT differences at four spectral regions: (a) $650-681.88 \mathrm{~cm}^{-1}$, (b) $889-903 \mathrm{~cm}^{-1}$, (c) 1380.0 $1410.00 \mathrm{~cm}^{-1}$, and (d) $2190-2260 \mathrm{~cm}^{-1}$. The red, blue, and black dots indicate the BT differences from north SNOs, south SNOs, and tropical SNOs.

$2400 \mathrm{~cm}^{-1}$. No matter whether CrIS and IASI are compared at finest spectral scale or boxcar-averaged spectral regions, all the studies show CrIS is slightly warmer than IASI at LWIR band. However, CrIS-IASI comparison is limited to the polar regions and thus future studies should extend the comparison into the mid-latitude and tropical regions. The double difference method relative to a common transfer target (e.g., a transfer radiometer and radiative transfer model simulations) may be feasible in future studies.

As a final note, we would like to point out that, given the fact that the radiometric differences do exist between hyperspectral instruments, the intercalibration community should be cautious to use only one hyperspectral sounder as a prime reference. A best practice should compare the broad- or narrow-band instruments against all four hyperspectral sounders to avoid biasing the results.

\section{Conclusions}

The radiometric and spectral consistency among AIRS, IASI, and CrIS is fundamental for the creation of long-term IR hyperspectral radiance benchmark data set for both intercalibration and climate-related studies. In this study, we directly compare the SNPP CrIS radiance measurements with IASI on MetOp-A and MetOp-B at the finest spectral scale and with AIRS on Aqua at selected 25 spectral regions through 1 year's SNO observations to evaluate radiometric consistency and differences of these four hyperspectral IR sounders. The spectra from different sounders are paired together through strict spatial and temporal collocation. The uniform scenes are selected by examining the collocated VIIRS pixels. The radiometric BT differences are then calculated by converting the spectra onto common spectral grids. The following conclusion can be drawn based on our analysis. 
CrIS agrees well with IASI on MetOp-A and IASI on MetOp-B at LWIR and MWIR bands with 0.1-0.2 K differences and CrIS is slightly warmer than IASI.

The largest BT differences are found at the spectral transition region (about $2400 \mathrm{~cm}^{-1}$ ) at SWIR band for both CrISIASI/A and CrIS-IASI/B SNO data sets. The root cause still needs further investigation in the future.

CrIS-IASI BT differences show weak scene-dependent patterns revealed from both CrIS-IASI/A and CrIS-IASI/B SNO data sets, which, however, are limited to the observations at the polar regions.

CrIS and AIRS are compared along the 25 spectral regions for both polar and tropical SNOs. The combined global SNO data sets indicate that the CrIS-AIRS BT differences are less than or around $0.1 \mathrm{~K}$ among 21 of 25 comparison spectral regions and they range from 0.15 to $0.21 \mathrm{~K}$ in the remaining four spectral regions. Moreover, among 16 of 25 spectral regions, CrIS is slightly warmer than AIRS. CrIS-AIRS BT differences shows weak scene-dependent features in some comparison spectral regions.

As a final note, we point out that, due to the huge volume of AIRS, IASI, and CrIS data, this study is only limited to a 1 -year period. CrIS has been operated in the full spectral resolution mode with 2211 channels since December 2014. This comparison will be extended to CrIS full resolution spectra to further examine the consistence of CrIS with AIRS and IASI.

Acknowledgements. The VIIRS and IASI data for this paper are available at NOAA's Comprehensive Large Array-data Stewardship System. The AIRS data are available at NASA Goddard Earth Sciences (GES) Data and Information Services Center (DISC). The IASI data can also be downloaded from European Organisation for the Exploitation of Meteorological Satellites (EUMETSAT) data center. The CrIS data for this paper are available at the data server at NOAA/NESDIS/STAR and can be obtained by contacting the authors at wlikun@umd.edu. The authors thank two anonymous reviewers, as well as Fangfang Yu and Frank Padula, for providing valuable comments for the study. This study is funded by the NOAA JPSS Program Office. Likun Wang and Yong Chen are also supported by NOAA grant NA14NES4320003 (Cooperative Institute for Climate and Satellites) at the University of Maryland/ESSIC. The manuscript contents are solely the opinions of the authors and do not constitute a statement of policy, decision, or position on behalf of NOAA or the U.S. government.

Edited by: F. Hase

\section{References}

Cao, C., Weinreb, M., and Xu, H.: Predicting simultaneous nadir overpasses among polar-orbiting meteorological satellites for the intersatellite calibration of radiometers, J. Atmos. Ocean. Tech., 21, 537-542, 2004.
Chahine, M. T., Pagano, T. S., Aumann, H. H., Atlas, R., Barnet, C., Blaisdell, J., Chen, L., Divakarla, M., Fetzer, E. J., Goldberg, M., Gautier, C., Granger, S., Hannon, S., Irion, F. W., Kakar, R., Kalnay, E., Lambrigtsen, B. H., Lee, S.-Y., Le Marshall, J., Wallace McMillan, W., McMillin, L., Olsen, E. T., Revercomb, H., Rosenkranz, P., Smith, W. L., Staelin, D., Strow, L. L., Susskind, J., Tobin, D., Wolf, W., and Zhou, L. : AIRS: improving weather forecasting and providing new data on greenhouse gases, B. Am. Meteorol. Soc., 87, 911-926, 2006.

Chen, Y., Han, Y., Tremblay, D., Wang, L., Jin, X., and Weng, F.: CrIS Full Resolution Processing and Validation System for JPSS, in: 19 International TOVS Study Conference, 26 March-1 April 2014, Jeju Island, South Korea, available at: http://cimss.ssec.wisc.edu/itwg/itsc/itsc19/program/ papers/1p_06_chen.pdf, last access: 1 August 2014.

Clough, S. A., Iacono, M. J., and Moncet, J.-L.: Line-by-line calculations of atmospheric fluxes and cooling rates: application to water vapor, J. Geophys. Res.-Atmos., 97, 15761-15785, doi:10.1029/92jd01419, 1992.

Clough, S. A., Shephard, M. W., Mlawer, E. J., Delamere, J. S., Iacono, M. J., Cady-Pereira, K., Boukabara, S., and Brown, P. D.: Atmospheric radiative transfer modeling: a summary of the AER codes, J. Quant. Spectrosc. Ra., 91, 233-244, doi:10.1016/j.jqsrt.2004.05.058, 2005.

Genest, J. and Tremblay, P.: Instrument line shape of Fourier transform spectrometers: analytic solutions for nonuniformly illuminated off-axis detectors, Appl. Optics, 38, 5438-5446, doi:10.1364/ao.38.005438, 1999.

Goldberg, M., Ohring, G., Butler, J., Cao, C., Datla, R., Doelling, D., Gärtner, V., Hewison, T., Iacovazzi, B., Kim, D., Kurino, T., Lafeuille, J., Minnis, P., Renaut, D., Schmetz, J., Tobin, D., Wang, L., Weng, F., Wu, X., Yu, F., Zhang, P., and Zhu, T.: The global space-based iinter-calibration system, B. Am. Meteorol. Soc., 92, 467-475, doi:10.1175/2010bams2967.1, 2011.

Han, Y., Revercomb, H., Cromp, M., Gu, D., Johnson, D., Mooney, D., Scott, D., Strow, L., Bingham, G., Borg, L., Chen, Y., DeSlover, D., Esplin, M., Hagan, D., Jin, X., Knuteson, R., Motteler, H., Predina, J., Suwinski, L., Taylor, J., Tobin, D., Tremblay, D., Wang, C., Wang, L., Wang, L., and Zavyalov, V.: Suomi NPP CrIS measurements, sensor data record algorithm, calibration and validation activities, and record data quality, J. Geophys. Res.-Atmos., 118, 2013JD020344, doi:10.1002/2013jd020344, 2013.

Hilton, F., Armante, R., August, T., Barnet, C., Bouchard, A., Camy-Peyret, C., Capelle, V., Clarisse, L., Clerbaux, C., Coheur, P.-F., Collard, A., Crevoisier, C., Dufour, G., Edwards, D., Faijan, F., Fourrié, N., Gambacorta, A., Goldberg, M., Guidard, V., Hurtmans, D., Illingworth, S., Jacquinet-Husson, N., Kerzenmacher, T., Klaes, D., Lavanant, L., Masiello, G., Matricardi, M., McNally, A., Newman, S., Pavelin, E., Payan, S., Péquignot, E., Peyridieu, S., Phulpin, T., Remedios, J., Schlüssel, P., Serio, C., Strow, L., Stubenrauch, C., Taylor, J., Tobin, D., Wolf, W., and Zhou, D.: Hyperspectral Earth observation from IASI: five years of accomplishments, B. Am. Meteorol. Soc., 93, 347-370, doi:10.1175/bams-d-11-00027.1, 2012.

Huang, X., Yang, W., Loeb, N. G., and Ramaswamy, V.: Spectrally resolved fluxes derived from collocated AIRS and CERES measurements and their application in model evaluation: clear sky 
over the tropical oceans, J. Geophys. Res.-Atmos., 113, D09110, doi:10.1029/2007jd009219, 2008.

Jouglet, D., Chinaud, J., and Lenot, X.: Radiometric intercomparison of IASI:IASI-A/IASI-B, IASI/AIRS, IASI/CrIS, in: The 2014 EUMETSAT Meteorological Satellite Conference, 2226 September 2014, 205, Geneva, Switzerland, 2014.

Pagano, T. S., Aumann, H. H., Hagan, D. E., and Overoye, K.: Prelaunch and in-flight radiometric calibration of the Atmospheric Infrared Sounder (AIRS), IEEE T. Geosci. Remote, 41, 265-273, doi:10.1109/tgrs.2002.808324, 2003.

Schreier, M. M., Kahn, B. H., Eldering, A., Elliott, D. A., Fishbein, E., Irion, F. W., and Pagano, T. S.: Radiance comparisons of MODIS and AIRS using spatial response information, J. Atmos. Ocean. Tech., 27, 1331-1342, doi:10.1175/2010jtecha1424.1, 2010.

Strow, L., Motteler, H., Schou, P., and Hannon, S. E.: Intercalibration of IASI with AIRS and CrIS, in: the Third Infrared Atmospheric Sounding Interferometer conference, 4-8 February 2013, Hyères, France, 2013a.

Strow, L. L., Motteler, H., Tobin, D., Revercomb, H., Hannon, S., Buijs, H., Predina, J., Suwinski, L., and Glumb, R.: Spectral calibration and validation of the Cross-track Infrared Sounder on the Suomi NPP satellite, J. Geophys. Res.-Atmos., 118, 1248612496, doi:10.1002/2013jd020480, 2013 b.

Tobin, D., Revercomb, H., and Antonelli, P.: Principal Component Analysis of IASI Spectra with a Focus on Non-Uniform Scene Effects on the ILS, Current Problems in Atmospheric Radiation (IRS 2008): Proceedings of the International Radiation Symposium (IRC/IAMAS), 3-8 August 2008, Foz do Iguaçu, Brazil, AIP Publishing, Melville, NY, USA, 16-19, 2009.

Tobin, D., Revercomb, H., Knuteson, B., Best, F., Taylor, J., Deslover, D., Borg, L., Moeller, C., Martin, G., Kuehn, R., Quinn, G., and Garcia, R.: Soumi NPP/JPSS CrossTrack Infrared Sounder (CrIS): Intercalibration with AIRS, IASI, and VIIRS, in: The 93rd AMS Annual Meeting, 610 January 2013, Austin, Texas, USA, available at: https: //ams.confex.com/ams/93Annual/webprogram/Manuscript/ Paper224176/Tobin_CrIS_AMS2013_10Feb2013.pdf (last access: 1 January 2015), 2013a.

Tobin D., Revercomb, H., Knuteson, R., Taylor, J., Best, F., Borg, L., DeSlover, D., Martin, G., Buijs, H., Esplin, M., Glumb, R., Han, Y., Mooney, D., Predina, J., Strow, L., Suwinski, L., and Wang, L.: Suomi-NPP CrIS radiometric calibration uncertainty, J. Geophys. Res.-Atmos., 118, 10589-510600, doi:10.1002/jgrd.50809, 2013b.
Uprety, S., Cao, C., Xiong, X., Blonski, S., Wu, A., and Shao, X.: Radiometric intercomparison between Suomi-NPP VIIRS and aqua MODIS reflective Solar bands using simultaneous nadir overpass in the low latitudes, J. Atmos. Ocean. Tech., 30, 27202736, doi:10.1175/jtech-d-13-00071.1, 2013.

Wang, L., Cao, C., and Goldberg, M.: Intercalibration of GOES-11 and GOES-12 water vapor channels with MetOp IASI Hyperspectral Measurements, J. Atmos. Ocean. Tech., 26, 1843-1855, doi:10.1175/2009jtecha1233.1, 2009a.

Wang, L., Wu, X., Goldberg, M., Cao, C., Li, Y., and Sohn, S.-H.: Comparison of AIRS and IASI radiances using GOES imagers as transfer radiometers toward climate data records, J. Appl. Meteorol. Clim., 49, 478-492, doi:10.1175/2009jamc2218.1, $2009 \mathrm{~b}$.

Wang, L., Goldberg, M., Liu, X., and Zhou, L.: Assessment of reanalysis datasets using AIRS and IASI hyperspectral radiances, Geoscience and Remote Sensing Symposium (IGARSS), 2010 IEEE International, Honolulu, Hawaii, USA, 25-30 July 2010, 2936-2939, 2010.

Wang, L., Goldberg, M., Wu, X., Cao, C., Iacovazzi Jr., R. A., Yu, F., and $\mathrm{Li}, \mathrm{Y}$.: Consistency assessment of atmospheric infrared sounder and infrared atmospheric sounding interferometer radiances: double differences vs. simultaneous nadir overpasses, J. Geophys. Res., 116, D11111, doi:10.1029/2010jd014988, 2011.

Wang, L., Han, Y., Tremblay, D., Weng, F., and Goldberg, M.: Intercomparison of NPP/CrIS radiances with VIIRS, AIRS, and IASI: a post-launch calibration assessment, Proc. SPIE 8528, Earth Observing Missions and Sensors: Development, Implementation, and Characterization II, 85280J, doi:10.1117/12.978769, 2012.

Wang, L., Tremblay, D. A., Han, Y., Esplin, M., Hagan, D. E., Predina, J., Suwinski, L., Jin, X., and Chen, Y.: Geolocation assessment for CrIS sensor data records, J. Geophys. Res.-Atmos., 118, 12690-12704, doi:10.1002/2013jd020376, 2013.

Wielicki, B. A., Young, D. F., Mlynczak, M. G., Thome, K. J., Leroy, S., Corliss, J., Anderson, J. G., Ao, C. O., Bantges, R., Best, F., Bowman, K., Brindley, H., Butler, J. J., Collins, W., Dykema, J. A., Doelling, D. R., Feldman, D. R., Fox, N., Huang, X., Holz, R., Huang, Y., Jin, Z., Jennings, D., Johnson, D. G., Jucks, K., Kato, S., Kirk-Davidoff, D. B., Knuteson, R., Kopp, G., Kratz, D. P., Liu, X., Lukashin, C., Mannucci, A. J., Phojanamongkolkij, N., Pilewskie, P., Ramaswamy, V., Revercomb, H., Rice, J., Roberts, Y., Roithmayr, C. M., Rose, F., Sandford, S., Shirley, E. L., Smith, W. L., Soden, B., Speth, P. W., Sun, W., Taylor, P. C., Tobin, D., and Xiong, X.: Achieving climate change absolute accuracy in orbit, B. Am. Meteorol. Soc., 94, 1519-1539, doi:10.1175/bams-d-12-00149.1, 2013. 